\title{
COMMENTARIES
}

\section{Perfecting the Pitch: What Constitutes Sufficient Contribution to Give Rise to Joint Authorship?}

\author{
Alexandros Antoniou \\ University of Essex, GB \\ a.antoniou@essex.ac.uk
}

\begin{abstract}
The article discusses the Intellectual Property Enterprise Court (IPEC) judgment on the 'Florence Foster Jenkins' case, which concerned the nature and extent of the defendant's contribution to the writing of a screenplay and whether that contribution was sufficient to give rise to joint authorship in a copyright work within the meaning of the Copyright, Designs and Patents Act 1998. It considers the distinction between 'primary' and 'secondary' skill proposed by the court and the significance of the decision for the industry.
\end{abstract}

Keywords: copyright; screenplay; joint authorship; sufficient contribution

\section{Background}

The dispute in Martin \& Anor v Kogan \& Ors [2017] EWHC 2927 arose between a professional writer of film and television scripts, Nicholas Martin, and a professional operatic singer, Julia Kogan, over the screenplay of the acclaimed film Florence Foster Jenkins. The film is a comedy drama starring Meryl Streep and Hugh Grant, and tells the story of a New York socialite 'whose unquenchable ambition to sing triumphed over what was probably the most complete and absolute lack of talent ever publicly displayed in Manhattan' (Sargeant 1945: 54). Mr Martin and Ms Kogan lived together as partners when the idea about the film was born and when early drafts of the screenplay were written. It was accepted that the couple frequently discussed the project. By the time Mr Martin produced the final draft used to shoot the film, their relationship had turned irreversibly sour. The film premiered in April 2016, crediting Mr Martin as the screenplay's sole author.

The claimants, Mr Martin and his company, sought a declaration that the first claimant was the sole author of the screenplay for the film and the defendant counterclaimed for a declaration that she was joint author of the screenplay and that both claimants had infringed her copyright in it. Ms Kogan contended that her creative work, originally contained within the first three drafts of the script, had found its way into the fourth and final version, of which it formed a substantial part. She was thus entitled to claim joint authorship of the final screenplay and sought a proportion of Mr Kogan's income from the film.

Section 10 of the Copyright, Designs and Patents Act 1988 defines a work of joint authorship as a work produced by the collaboration of two or more authors in which the contribution of each author is not distinct from that of the other author or authors.' The onus is on the person asserting joint authorship to prove his or her case (Brown v Mcasso Music Production Ltd [2005] FSR 40). Under the 1988 Act, two requirements must be satisfied for joint authorship to arise: first, the work must have been created by the collaboration of two or more authors; and second, the creative contribution of each author must not be distinct from that of the other author with whom there was a collaboration. In addition to these requirements, it is well established that each party must have contributed to the act of authorship of the work at issue. A joint author is ipso facto an author within the meaning of section 9(1) of the Act and must have therefore added a sufficient level of authorial skill and labour to earn a joint copyright ownership (Fylde Microsystems Ltd v Key Radio Systems Ltd [1998] FSR 449, at p. 455 per Laddie J). Thus, a claimant must also show that he or she made a significant and original contribution to the collaborative effort which 'approximates to penmanship' (Robin Ray $v$ Classic FM Plc [1998] FSR 622, at 636 per Lightman J). Although it was not disputed in this case that the condition concerning absence of distinction in contributions was met, the IPEC judge, Hacon J, held that Ms Kogan failed to meet the criterion of 'collaboration' between two or more authors and the implied criterion of 'sufficient contribution' to qualify as a joint author of the work. 


\section{Collaboration}

Based on documentary evidence, Hacon J found that the actual screenplay of the film was written after the final breakdown of the personal relationship between Mr Martin and Ms Kogan. Unlike previous drafts, the parties had not discussed the final version and there was no collaboration between them in creating it. Ms Kogan's consent to the use of her material generated for the first to third drafts in the final screenplay was 'no doubt necessary for collaboration, but not sufficient' (Martin, at para. 25). There must have been a 'common design' (Martin, at para. 25, applying Levy $v$ Rutley [1870-71] LR 6 CP 523, at p. 529 per Keating J), i.e. 'co-operative acts by the authors, at the time the copyright work in issue was created, which led to its creation' (Martin, at para. 54, point 1).

\section{The Ultimate Arbiter test}

It was accepted in this case that Mr Martin had had the final word as to what would go in all the draft screenplays. It was argued on behalf of the claimants that Mr Martin was the 'ultimate arbiter' (Martin, at para. 28) and therefore, the sole author of all the drafts. Criticism or editing suggestions from a putative joint author will not normally lead to joint authorship where the main author has the final saying in relation to the form and content of the work. However, Hacon J rejected an 'absolutist' (Martin, at para. 29) application of this principle. The status of an author as an ultimate arbiter can be 'highly relevant' (Martin, at para. 29) when determining whether there is joint authorship, but it is not a decisive factor on its own (Martin, at para. 54, points 8 and 9).

\section{Sufficient Contribution}

In assessing whether Ms Kogan had sufficiently contributed to the shooting script, Hacon J considered several authorities on what sort of contribution to a work qualifies someone as a joint author: adding elements which are not themselves subject to copyright protection, such as scenic effects to a play, or supplying certain catch lines in the dialogue do not amount to a sufficient contribution (Tate $v$ Thomas [1921] 1 Ch 503); offering constructive criticism in the context of transforming a novel into a play is not a sufficient contribution either (Wiseman v George Weidenfeld \& Nicholson Ltd [1985] FSR 525); the expenditure of skill, time and effort in testing and debugging a computer software is more akin to proofreading and does not constitute a contribution to the authoring of a source code (Fylde Microsystems Ltd $v$ Key Radio Systems Ltd [1998] FSR 449, at p. 457 per Laddie J); a joint author must do more than contribute ideas to an author; 'what is essential is a direct responsibility for what appears on paper' (Robin Ray v Classic FM plc [1998] FSR 622, at p. 636 per Lightman J). Furthermore, a director's contributions to the interpretation and presentation of a play during rehearsals and minor changes to its plot are insufficient to make him or her a joint author. The contribution needs to be towards the creation of the dramatic work (Brighton $v$ Jones [2004] EWHC 1157). Finally, to be sufficient, the contribution must consist in 'a significant part of the skill and labour' (Cala Homes (South) Ltd v Alfred McAlpine Homes East Ltd [1995] FSR 818, at pp. 835-6 per Laddie J) and therefore must contribute towards the originality of the work; not just to the mechanical act of fixation.

In the case under consideration, Ms Kogan's textual and non-textual contributions to the first three drafts 'never rose above the level of providing useful jargon, along with helpful criticism and some minor plot suggestions' (Martin, at para. 85). As such, these were insufficient to qualify her as a joint author of the final screenplay, 'even had those contributions all been made in the course of a collaboration' (Martin, at para. 85) to create it. Mr Martin was therefore entitled to a declaration that he was the sole author of the screenplay and that the claimants had not infringed the copyright in it.

Hacon J further explained that the significance of a contribution which forms part of the creation of the work depends on the 'type of skill' (Martin, at para. 43) used in making that contribution. The judge supported this by introducing a new distinction between 'primary skills' (e.g. physically using a pencil to create an image or choosing, organising, integrating and juxtaposing words in writing a novel) and 'secondary skills' (e.g. inventing plot in the case of a novel or selecting colour when painting). This differentiation does not imply that the latter are necessarily less important in the creative process. Although both types are inherently capable of giving rise to joint authorship, for evidential reasons 'it may often be harder to establish joint authorship solely by reference to secondary skills' (Martin, para. 51 and para. 54, point 4).

\section{Comment}

Several parties often get involved in the creative process of a copyright work, with one or more of them feeling that they should be credited for their input which was ultimately weaved into the fabric of a new work. Evaluating a contribution's sufficiency is not an easy feat. The Florence Foster Jenkins judgment provides a useful overview of the current law concerning the conditions under which joint authorship arises in England and Wales. In evaluating a putative joint author's contribution, it introduces a consideration of whether he or she has contributed by way of primary or secondary skill. It is arguable that no clear explanation is offered about how deliberately subjective creative choices are to be labelled and classified under this binary distinction. It would not be unreasonable to suggest that the structure of events in a novel is as crucial for its originality as the arrangement of words. Indeed, Aristotle stresses 
the primacy of the plot - the soul of the action - over the characters' eloquent speeches and other components of drama (Kaufmann 1968: 55). The judgment would have been more helpful, had it offered a more systematic method of associating creative choices to certain types of skill, especially in light of the judge's observation that 'case law sets the bar high when it comes to secondary skills' (Martin, at para. 51). If this distinction becomes well-established in English case law, it is uncertain whether it can be expected to yield predictable results and induce clarity in the assessment of authorial contributions and rewards linked to the genesis of a work.

Whilst there was no intention to create a hierarchy in skills as components of the creative process, the judge commented that it would be less difficult to find joint authorship in relation to contributions involving primary skills, as opposed to contributions involving secondary skills. It may be suggested that this division has little merit. What Hacon J describes as secondary skills would be similar to ideas which are so abstract or commonplace as not to form a substantial part of the whole of the work in issue (Designers Guild Ltd $v$ Russell Williams Textiles Ltd [2001] FSR 11, at para. 25 per Lord Hoffmann), and thus constitute insufficient contributions. Where the contribution relied upon is the product of ideas which are too remote from the work as expressed, it will often be harder to prove joint authorship. Primary skills, on the other hand, would be akin to forms of protectable expression. This binary distinction may therefore be seen as a reiteration of the idea/expression dichotomy in another guise.

Moreover, Hacon J placed in this case very little reliance on witnesses' memory of what was stated in conversations and meetings. This raises a point of practical significance: litigation parties should avoid the fallacy of placing much emphasis on evidence based on witness recollection. The judge questioned the extent to which this provides a veridical and reliable recorder of events as experienced. Instead, he based factual findings on inferences drawn from documentary evidence (Martin, at para. 61). This case serves as a reminder of the importance of carefully documenting any contribution to a copyright work. Individuals considering themselves as authors who have collaborated in, and contributed to, the creation of the final draft of a work should keep as much of the background work as possible from the very outset and maintain accurate records that identify the extent to which they exercised control over the final work and the consistency with which they manifested their intent to be treated as joint authors. Previous case law demonstrates the significance, and perhaps necessity, of agreeing authorship before any work is created (Fisher $v$ Brooker [2009] FSR 25). The Florence Foster Jenkins case also stresses the importance of having effective intellectual property management processes in place. Authorship of screenplays needs to be subjected to extensive and meticulous appraisals by feature film production companies to capture all the necessary rights attached and ensure unrestricted freedom to operate in respect of their assets.

However, it should be noted that the issue of joint authorship in Florence Foster Jenkins arose in the context of a personal relationship, in which rigid negotiation processes and more corporate notions of formalised agreements and record-keeping would seem, to say the least, incongruous. Although clarity over the criteria for authorship is the preferred approach and can be useful in minimising tensions, it is less probable that putative collaborators in the informal setting of a personal relationship will spend time and energy on the onset of a project in ascertaining roles or strict responsibilities. Consequently, the potential for a joint contribution may not be easily detected, for example, in a pre-audit planning activity for film production purposes. Thus, cases such as the one under consideration are likely to come before the courts from time to time, despite Hacon J's systematic exposition of the law relating to joint-authorship.

\title{
Competing Interests
}

The author has no competing interests to declare.

\section{References}

Kaufmann, W. 1968. Tragedy and Philosophy. Princeton, NJ: Princeton University Press. Sargeant, W. 1945. Soprano's Progress. Life, 54. 26 March.

\author{
Cases cited \\ Brighton v Jones [2004] EWHC 1157. \\ Brown v Mcasso Music Production Ltd [2005] FSR 40. \\ Cala Homes (South) Ltd v Alfred McAlpine Homes East Ltd [1995] FSR 818. \\ Designers Guild Ltd v Russell Williams Textiles Ltd [2001] FSR 11. \\ Fisher v Brooker [2009] FSR 25. \\ Fylde Microsystems Ltd v Key Radio Systems Ltd [1998] FSR 449. \\ Levy v Rutley [1870-71] LR 6 CP 523. \\ Martin \& Anor v Kogan \& Ors [2017] EWHC 2927. \\ Robin Ray v Classic FM Plc [1998] FSR 622. \\ Tate $v$ Thomas [1921] 1 Ch 503. \\ Wiseman v George Weidenfeld \& Nicholson Ltd [1985] FSR 525.
}


How to cite this article: Antoniou, A. 2018. Perfecting the Pitch: What Constitutes Sufficient Contribution to Give Rise to Joint Authorship? Entertainment and Sports Law Journal, 16: 2, pp. 1-4, DOl: https://doi.org/10.16997/eslj.217

Submitted: 01 March 2018 Accepted: 26 March 2018 Published: 02 July 2018

Copyright: ๑ 2018 The Author(s). This is an open-access article distributed under the terms of the Creative Commons Attribution 4.0 International License (CC-BY 4.0), which permits unrestricted use, distribution, and reproduction in any medium, provided the original author and source are credited. See http://creativecommons.org/licenses/by/4.0/.

$\mathrm{u}[\quad$ Entertainment and Sports Law Journal is a peer-reviewed open access journal published by Ubiquity Press. 